- 研究报告・

\title{
中国地衣的濒危等级评估
}

\author{
魏金金丽 ${ }^{1}$ 邓 红 $^{1}$ 魏江春 ${ }^{1,2 *}$ \\ 1 (中国科学院微生物研究所真菌学国家重点实验室, 北京 100101) \\ 2 (中国科学院大学, 北京 100049)
}

\begin{abstract}
摘要: 地衣是大型真菌的重要组成部分, 是中国大型真菌红色名录评估的主要对象之一。本次评估的地衣共2,164 种, 其中子囊菌地衣2,145种, 担子菌地衣19种, 分属于 $2 门 9$ 纲34目92科352属。评估结果显示, 地衣受威胁物种共 28 种, 占被评估地衣物种总数的 $1.29 \%$, 其中极危 3 种, 濒危 7 种, 易危 18 种; 近危 6 种, 无危 657 种, 而数据不足的 物种达 1,473 种。这类因为缺乏足够的数据资料而未能进一步评估其生存状态和红色名录等级的物种占评估地衣总 数的 $68.07 \%$, 凸显了我国地衣学研究的严峻形势及对地衣分类学人才的迫切需要。对受威胁物种的分析表明, 地 衣由于自身生长缓慢和对环境污染敏感, 并且绝大多数分布区域狭窄, 种群数量少, 对生境退化的适应和恢复生 长的能力弱, 人类活动和气候变化导致的栖息地破坏和碎片化使得这些地衣的生存受到严重威胁。值得注意的是, 评为易危的一些地衣, 因具有较大的食药用价值而被过度采挖利用, 如不采取有效保护措施, 其受威胁程度将进 一步加剧。
\end{abstract}

关键词: IUCN红色名录; 受威胁类群; 评估; 地衣; 中国

\section{Threatened categories assessment of lichens in China}

Xinli Wei ${ }^{1}$, Hong Deng ${ }^{1}$, Jiangchun Wei ${ }^{1,2^{*}}$

1 State Key Laboratory of Mycology, Institute of Microbiology, Chinese Academy of Sciences, Beijing 100101

2 University of Chinese Academy of Sciences, Beijing 100049

\begin{abstract}
Lichens are important components of macrofungi, and thus they are also main subjects in the Red List Assessment of Macrofungi in China. A total of 2,164 lichen species were evaluated here, including 2,145 ascomycete lichen species and 19 basidiomycete lichen species. These species were organized into 2 phyla, 9 classes, 34 orders, 92 families and 352 genera. The results showed that, of the 28 species identified as threatened, 3 species were Critically Endangered (CR), 7 species were Endangered (EN) and 18 species were Vulnerable (VU). These 28 represented 1.29\% of all evaluated species, with 6 other species considered to be Near Threatened (NT) and 657 species assessed as Least Concern (LC). More than half the species, 1,473 (68.07\%), were Data Deficient (DD) and could not be further evaluated due to lack of data. This highlights the severe lack of lichen research and the urgent need for lichen taxonomists in China. The extremely slow growth, weak adaptability to habitat degradation, particular sensitivity to air pollution, narrow distribution and small population size characteristic of lichens all contribute to the susceptible state of lichens that face habitat destruction caused by human activities. In addition, it is worth noting that some lichen species evaluated as Vulnerable here, have since been overexploited due to their edibility and well-known medicinal value. These species' conservation status will be further aggravated if they continue to lack effective protection.
\end{abstract}

Key words: IUCN red list; endangered taxa; assessment; lichen; China

地衣是由地衣型真菌作为建群种(constructive species)与相应的藻类或蓝细菌作为伴生种 (com- panion species)而结成的稳定胞外共生生命支撑系 统, 即菌藻共生群落。至于建群种和伴生种之外的

收稿日期: 2019-05-07; 接受日期: 2019-07-11

基金项目: 生态环境部生物多样性调查评估项目(2019HJ2096001006)和国家自然科学基金(31770022)

* 通讯作者 Author for correspondence. E-mail: weijc2004@126.com 
所谓第三种生命(Spribille et al, 2016)则为偶见种 (accidental species), 如地衣体的内衣㾉和外衣㾉中 的蓝细菌、地衣体的内生真菌(endolichenic fungi)、外 生真菌(lichenicolous fungi)以及外生地衣(lichenicolous lichens)等。有的偶见种稳定出现在个别地衣上, 有的则偶然与不同地衣相关联。因此, 在稳定的地 衣菌藻共生群落中, 除建群种和伴生种之外的多种 多样的偶见种并不限于第三种生命, 而是生物多样 性无处不在的实际表现。世界范围已知地衣分隶于 8纲39目115科995属, 共19,387种(Lücking et al, 2017), 约占已知真菌物种总数的20\% (Hawksworth, 1991), 子囊菌的 $40 \%$ (Kirk et al, 2008)。我国已报道的地衣 共3,082种(Wei，2020), 约占中国大型真菌总数(约1 万种)的 $30 \%$, 占全世界已报道地衣总种数的 $15 \%$ 。

地衣是岩石风化和土壤形成的先锋生物(Lindsay, 1978; Chen et al, 2000), 尤其在地球南北极地和 高寒地区以及干旱荒漠为优势类群, 所占陆地面积 为地球总面积的 $8 \%$ 以上(Larson, 1987), 具有重要 的生态功能。地衣中含有独特的次生代谢产物, 在 抗艾滋病(Neamati et al, 1997)、抗癌(Mitrović et al, 2011; Pavlovic et al, 2012)、抗菌(Ranković et al, 2008) 及提高人体免疫力(Pavlovic et al, 2012)等方面也具 有良好的应用潜力。

由于地衣的结构特点和生理特性, 如缺乏植物 那样具保护作用的真皮层及蜡质层, 且光合共生物 多为共球藻(Trebouxia sp.), 地衣体结构脆弱易损坏, 对大气污染极度敏感。空气中的二氧化硫、氟化物、 重金属离子以及放射性物质等都是敏感的污染源。 因此, 地衣多分布于远离空气污染的南北两极、高 山、原始森林和荒漠等环境。人类活动的不断加剧, 尤其是自然生态系统的破坏及对那些具有医药用 途及保健作用的地衣的过度采挖, 使地衣生物多样 性受到严重破坏。地衣在自然界中生长极为缓慢, 受到破坏后很难恢复。对地衣生物多样性现状进行 评估, 首先需要了解其生存状态。

\section{国内外地衣受威胁状态评估现状}

世界自然保护联盟(IUCN)从20世纪80年代开 始起草与制定《生物多样性公约》, 并于1992年讨 论通过, 旨在保护地球生物多样性和可持续利用生 物资源(Glowka et al, 1997)。了解生物多样性现状需 要对物种濒危状况进行评估, 这是实施生物多样性
优先保护的重要前提(Mace \& Lande, 1991; Vié et al, 2008), 对于制订物种保护管理策略尤为重要。1964 年, IUCN建立了濒危物种红色名录(简称“IUCN红 色名录”), 它是评价生物物种濒危和灭绝风险的最 好系统之一, 在世界各国得到广泛应用(de Grammont \& Cuarón, 2006; Miller et al, 2007)。

Church等(1997)出版的《英国地衣红皮书》，首 次利用IUCN标准对英国地衣生存状态进行了评 估。Woods和Coppins (2003，2012)出版了英国地衣 保育评估的专著, 其中2012版还包括了地衣生真菌, 评估结果显示 $69.4 \%$ 的物种状态为无危。 Randlane (1998)对爱沙尼亚的110种大型地衣进行了濒危状 况评估, 占该国大型地衣物种数的约33\%。Baillie 等(2004)发布的IUCN Red List of Threatened Species $^{T M}$. A Global Species Assessment表明, 在所有已 评估物种中, 共有 16,118种被视为受威胁种, 其中 动物 7,725 种, 植物 8,390 种, 地衣及菇类 3 种。 Randlane等(2008)第二次对爱沙尼亚地衣进行了评 估，参考和依据了2001、2003和2006年的IUCN评估 标准及流程, 评估对象包括地衣、地衣生真菌及与 地衣亲缘关系较近的腐生真菌共464种，占爱沙尼 亚上述物种总数的 $45.5 \%$, 其中 251 种被评为无危; 在213种被列于不同等级的红色名录中，濒危状态 的地衣有113种。爱沙尼亚对地衣的保护工作开始 时间也较早，从2004年起，即有51种地衣被列入爱 沙尼亚官方保护的名单中。日本京都2015年发布了 本地的地衣红色名录，在评估的163种地衣中，有 23种处于受威胁状态(http://www.pref.kyoto.jp/)。

从2004年开始中国启动中国物种红色名录编 制后, 共分为六卷进行了出版和发布, 其中第一卷 为9,000多个动植物种的红色名录，包括物种名称 (学名、中文名、英文名)、中国分布占全球的比例、 评估的濒危等级以及所依据的标准和理由、IUCN 全球评估等级等; 后五卷分别为脊椎动物、无脊椎 动物和植物卷册。2015年中国科学院和环境保护部 联合发布《中国生物物种名录》和《中国生物多样 性红色名录》。

云南省环境保护厅联合中国科学院昆明植物 研究所和昆明动物研究所从2016年起启动云南省 生物物种红色名录的编制工作，其中包括云南地衣 1,067种，历时一年于2017年出版和发布，是我国发 布的首个省级生物物种红色名录, 填补了我国地衣 
红色名录空白。在该名录中, 共有13种地衣被评为 云南省省级受威胁物种, 其中极危1种(金丝带Lethariella zahlbruckneri), 濒危3种(圆盘衣Gymnoderma coccocarpum、木生红盘衣Ophioparma handelii和曲 金丝Lethariella flexuosa), 易危6种(顶杯衣Acroscyphus sphaerophoroides、分枝柱衣Pilophorus fruticosus、毛面衣Erioderma meiocarpum、密枝小狍发 Bryoria fastigiata、金丝刷Lethariella cladonioides和 绿丝槽枝Sulcaria virens), 近危3种(雪地茶Thamnolia subuliformis、地荼 T. vermicularis和广开小孢发 Bryoria divergescens), 其他绝大部分物种被评为数 据不足。

\section{2 评估标准及流程}

为全面评估中国大型真菌包括地衣的受威胁 状况，原环境保护部联合中国科学院于2016年启动 了“中国生物多样性红色名录一大型真菌卷” (包 括大型子囊菌、大型担子菌和地衣型真菌等分卷) 的编制工作。本次评估以中国菌物名录数据库和搜 集的文献资料为基础, 通过大规模的快速篮选和初 步归类, 然后针对需要特别关注的物种, 依据中国 大型真菌红色名录评估等级与标准(王科等, 2020)
进行评估, 评估等级主要包括灭绝(Extinct, EX)、野 外灭绝(Extinct in the Wild, EW)、极危(Critically Endangered, CR)、濒危(Endangered, EN)、易危(Vulnerable, VU)、近危 (Near Threatened, NT)、无危 (Least Concern, LC)、数据不足(Data Deficient, DD)和未予 评估(Not Evaluated, NE)(IUCN, 2012)。

评估过程依照《中国大型真菌红色名录评估方 法和程序》(王科等, 2020)开展, 包括数据收集整理、 初评、函评、会评、复审、形成评估说明书等步骤。 全国从事地衣相关研究的 30 多位科研人员参与评 估，共同完成评估任务。

\section{3 评估结果}

本次评估地衣2,164种，其中子囊菌地衣2,145 种、担子菌地衣19种，分属于 $2 门 9$ 纲 34 目 92 科 352 属。评估物种数最多的纲为茶渍纲, 达 1,933 种, 占 被评估地衣物种总数的 $89.33 \%$; 评估物种数最多的 目为茶渍目, 有 866 种; 评估物种数最多的科为梅 衣科, 有469种(表1)。

评估结果表明，地衣受威胁物种共28种，占被 评估地衣物种总数的 $1.29 \%$ (表2)。其中极危 3 种，濒 危7种，易危18种。此外，近危的地衣共6种，占被评

表1 地衣评估类群物种数及不同评估等级物种数。CR: 极危; EN: 濒危; VU: 易危; NT: 近危; LC: 无危; DD: 数据不足。 Table 1 The species number of evaluated lichen taxa and different evaluated categories. CR, Critically Endangered; EN, Endangered; VU, Vulnerable; NT, Near Threatened; LC, Least Concern; DD, Data Deficient.

\begin{tabular}{|c|c|c|c|c|c|c|c|c|}
\hline 目 Order & 科 Family & 物种数 No. of species & CR & EN & VU & NT & LC & DD \\
\hline \multicolumn{9}{|l|}{ 子囊菌门 Ascomycota } \\
\hline 斑衣纲 Arthoniomycetes & & 50 & & & & & & \\
\hline \multirow[t]{5}{*}{ 斑衣目 Arthoniales } & 斑衣科 Arthoniaceae & 21 & & & & & 5 & 16 \\
\hline & 金絮衣科 Chrysotrichaceae & 3 & & & & & 1 & 2 \\
\hline & 黑斑衣科 Melaspileaceae & 1 & & & & & & 1 \\
\hline & 孔文衣科 Opegraphaceae & 2 & & & & & 1 & 1 \\
\hline & 染料衣科 Roccellaceae & 23 & & & & & 3 & 20 \\
\hline 粉头衣纲 Coniocybomycetes & & 2 & & & & & & \\
\hline 粉头衣目Coniocybales & 粉头衣科 Coniocybaceae & 2 & & & & & 1 & 1 \\
\hline 座軌菌纲 Dothideomycetes & & 36 & & & & & & \\
\hline 纤柔菌目 Abrothallales & 纤柔菌科 Abrothallaceae & 1 & & & & & & 1 \\
\hline 未定目 Incertae sedis & 未定科 Incertae sedis & 5 & & & & & 1 & 4 \\
\hline 衣外菌目 Lichenoconiales & 衣外菌科 Lichenoconiaceae & 2 & & & & & & 2 \\
\hline 单芽菌目 Monoblastiales & 单芽菌科 Monoblastiaceae & 10 & & & & & & 10 \\
\hline 球囊菌目 Mycosphaerellales & 球囊菌科 Mycosphaerellaceae & 2 & & & & & & 2 \\
\hline 格狍腔菌目 Pleosporales & 星核衣科Arthopyreniaceae & 2 & & & & & & 2 \\
\hline 叶上衣目 Strigulales & 叶上衣科 Strigulaceae & & & & & & & \\
\hline 乳嘴衣目 Trypetheliales & 乳嘴衣科 Trypetheliaceae & 10 & & & & & & 10 \\
\hline
\end{tabular}


表1 (续) Table 1 (continuous)

\begin{tabular}{|c|c|c|c|c|c|c|c|c|c|}
\hline 目 Order & 科 Family & 物种数 & No. of species & CR & EN & VU & NT & LC & DD \\
\hline 散囊菌纲 Eurotiomycetes & & 94 & & & & & & & \\
\hline 类胶目 Collemopsidiales & 黄核衣科 Xanthopyreniaceae & 1 & & & & & & & 1 \\
\hline 粉衣目 Mycocaliciales & 粉衣科 Mycocaliciaceae & 4 & & & 1 & & 1 & & 4 \\
\hline \multirow[t]{2}{*}{ 小核衣目 Pyrenulales } & 干瘤菌科 Celotheliaceae & 1 & & & & & & & 1 \\
\hline & 小核衣科 Pyrenulaceae & 14 & & & & & & & 14 \\
\hline 瓶口衣目 Verrucariales & 瓶口衣科 Verrucariaceae & 74 & & & & & & 8 & 66 \\
\hline 未定纲 Incertae sedis & & 1 & & & & & & & \\
\hline 未定目 Incertae sedis & 未定科 Incertae sedis & 1 & & & & & & 1 & \\
\hline 茶渍纲 Lecanoromycetes & & 1,933 & & & & & & & \\
\hline 微孢衣目 Acarosporales & 微狍衣科 Acarosporaceae & 30 & & & & & & 11 & 19 \\
\hline 极地衣目 Arctomiales & 极地衣科 Arctomiaceae & 1 & & & & & & & 1 \\
\hline \multirow{4}{*}{ 羊角衣目 Baeomycetales } & 柄盘衣科 Anamylopsoraceae & 1 & & & & & & & 1 \\
\hline & 羊角衣科 Baeomycetaceae & 7 & & & & & & 1 & 6 \\
\hline & 褐边衣科 Trapeliaceae & 13 & & & & & & 2 & 11 \\
\hline & 木刻衣科 Xylographaceae & 3 & & & & & & 2 & 1 \\
\hline 粉衣目 Caliciales & 粉衣科 Caliciaceae & 60 & & & & & & 10 & 49 \\
\hline 黄烛衣目 Candelariales & 黄烛衣科 Candelariaceae & 15 & & & & & & 2 & 13 \\
\hline 膜衣目 Hymeneliales & 膜衣科 Hymeneliaceae & 6 & & & & & & & 6 \\
\hline \multirow[t]{10}{*}{ 未定目 Incertae sedis } & 珠节衣科 Arthrorhaphidaceae & 4 & & & & & & & 4 \\
\hline & 锈病衣科 Brigantiaeaceae & 1 & & & & & & & 1 \\
\hline & 炭菌科 Carbonicolaceae & 1 & & & & & & & 1 \\
\hline & 盘耳衣科 Elixiaceae & 1 & & & & & & & 1 \\
\hline & 棕网盘科 Fuscideaceae & 4 & & & & & & 1 & 3 \\
\hline & 未定科 Incertae sedis & 3 & & & & & & 1 & 2 \\
\hline & 盾叶衣科 Ophioparmaceae & 2 & & & & & & 1 & 1 \\
\hline & 原乳衣科 Protothelenellaceae & 1 & & & & & & & 1 \\
\hline & 雉形狍科 Ropalosporaceae & 2 & & & & & & 1 & 1 \\
\hline & 乳衣科 Thelenellaceae & 2 & & & & & & & 2 \\
\hline \multirow[t]{17}{*}{ 茶渍目 Lecanorales } & 小蜡盘科 Biatorellaceae & 2 & & & & & & & 2 \\
\hline & 旋衣科 Byssolomataceae & 29 & & & & & & & 29 \\
\hline & 石荵科 Cladoniaceae & 109 & & 1 & 2 & 1 & 2 & 55 & 50 \\
\hline & 棉絮衣科 Crocyniaceae & 2 & & & & & & & 2 \\
\hline & 赤星衣科 Haematommataceae & 4 & & & & & & 1 & 3 \\
\hline & 茶渍科 Lecanoraceae & 111 & & 1 & & & & 27 & 83 \\
\hline & 柄座衣科 Malmideaceae & 3 & & & & & & & 3 \\
\hline & 托盘衣科 Megalariaceae & 1 & & & & & & & 1 \\
\hline & 黑红衣科 Mycoblastaceae & 2 & & & & & & & 2 \\
\hline & 梅衣科 Parmeliaceae & 469 & & 1 & 1 & 10 & 1 & 182 & 272 \\
\hline & 裸衣科 Psilolechiaceae & 1 & & & & & & & 1 \\
\hline & 鳞网衣科 Psoraceae & 8 & & & & 1 & & 1 & 6 \\
\hline & 树花科 Ramalinaceae & 75 & & & & & & 15 & 60 \\
\hline & 果衣科 Ramboldiaceae & 3 & & & & & & & 3 \\
\hline & 绦狍衣科 Scoliciosporaceae & 3 & & & & & & & 3 \\
\hline & 球粉衣科 Sphaerophoraceae & 4 & & & & & & 3 & 1 \\
\hline & 多狍衣科 Sporastatiaceae & & 2 & & & & & & 2 \\
\hline
\end{tabular}




\section{表1 (续) Table 1 (continuous)}

\begin{tabular}{|c|c|c|c|c|c|c|c|c|}
\hline 目 Order & 科 Family & 物种数 No. of species & CR & EN & VU & NT & LC & DD \\
\hline & 鳞茶渍科 Squamarinaceae & 6 & & & & & 2 & 4 \\
\hline & 珊瑚枝科 Stereocaulaceae & 31 & & & & & 4 & 27 \\
\hline & 峡狍菌科 Strangosporaceae & 1 & & & & & & 1 \\
\hline 网衣目 Lecideales & 网衣科 Lecideaceae & 48 & & & & & 9 & 39 \\
\hline 线枝目 Leprocaulales & 线枝科 Leprocaulaceae & 1 & & & & & & 1 \\
\hline \multirow[t]{7}{*}{ 厚顶盘目 Ostropales } & 线衣科 Coenogoniaceae & 6 & & & & & 1 & 5 \\
\hline & 楔形衣科 Gomphillaceae & 12 & & & & & 1 & 11 \\
\hline & 文字衣科 Graphidaceae & 184 & & & & & 60 & 124 \\
\hline & 凹盘衣科 Gyalectaceae & 5 & & & & & & 5 \\
\hline & 疱衣菌科 Phlyctidaceae & 2 & & & & & 1 & 1 \\
\hline & 污核衣科 Porinaceae & 15 & & & & & & 15 \\
\hline & 点盘菌科 Stictidaceae & 5 & & & & & & 5 \\
\hline \multirow[t]{7}{*}{ 地卷目 Peltigerales } & 瓦衣科 Coccocarpiaceae & 3 & & & & & 3 & \\
\hline & 胶衣科 Collemataceae & 69 & & & & & 33 & 36 \\
\hline & 肺衣科 Lobariaceae & 55 & & & & & 15 & 40 \\
\hline & 肾盘衣科 Nephromataceae & 12 & & & & & 2 & 10 \\
\hline & 鳞叶衣科 Pannariaceae & 23 & & & & & 9 & 14 \\
\hline & 地卷科 Peltigeraceae & 42 & & & & & 25 & 17 \\
\hline & 胎座衣科 Placynthiaceae & 4 & & & & & & 4 \\
\hline \multirow[t]{5}{*}{ 鸡皮衣目 Pertusariales } & 球孔衣科 Coccotremataceae & 1 & & & & & & \\
\hline & 霜降衣科 Icmadophilaceae & 8 & & & 1 & & 1 & 5 \\
\hline & 大孢衣科 Megasporaceae & 42 & & & & & 15 & 27 \\
\hline & 肉疮衣科 Ochrolechiaceae & 31 & & & & & 15 & 16 \\
\hline & 鸡皮衣科 Pertusariaceae & 74 & & & & & 37 & 36 \\
\hline \multirow[t]{2}{*}{ 地图衣目 Rhizocarpales } & 腊肠衣科 Catillariaceae & 10 & & & & & & 10 \\
\hline & 地图衣科 Rhizocarpaceae & 24 & & & 1 & & 5 & 18 \\
\hline \multirow[t]{4}{*}{ 黄枝衣目 Teloschistales } & 多极孢衣科 Letrouitiaceae & 1 & & & & & & 1 \\
\hline & 大孢衣科 Megalosporaceae & 4 & & & & & & 4 \\
\hline & 蜈蚣衣科 Physciaceae & 131 & & & 2 & & 52 & 77 \\
\hline & 黄枝衣科 Teloschistaceae & 49 & & & & & 13 & 36 \\
\hline 石耳目 Umbilicariales & 石耳科 Umbilicariaceae & 49 & & 3 & 2 & 3 & 12 & 32 \\
\hline 垂舌菌纲 Leotiomycetes & & 2 & & & & & & \\
\hline 维氏衣目 Vezdaeales & 维氏衣科 Vezdaeaceae & 2 & & & & & & 2 \\
\hline 异极衣纲 Lichinomycetes & & 27 & & & & & & \\
\hline \multirow[t]{2}{*}{ 异极衣目 Lichinales } & 异极衣科 Lichinaceae & 15 & & & & & 1 & 14 \\
\hline & 盾衣科 Peltulaceae & 12 & & & & & 1 & 11 \\
\hline \multicolumn{9}{|l|}{ 担子菌门 Basidiomycota } \\
\hline 蘑菇纲 Agaricomycetes & & 18 & & & & & & \\
\hline \multirow[t]{2}{*}{ 蘑菇目 Agaricales } & 蜡伞科 Hygrophoraceae & 5 & & & & & 2 & 3 \\
\hline & 口蘑科 Tricholomataceae & 1 & & & & & & 1 \\
\hline 鸡油菌目 Cantharellales & 锁珊菌科 Clavulinaceae & 7 & & & & & 1 & 6 \\
\hline 伏革菌目 Corticiales & 伏革菌科 Corticiaceae & 1 & & & & & & 1 \\
\hline 未定目 Incertae sedis & 未定科 Incertae sedis & 4 & & & & & & 4 \\
\hline 银耳纲 Tremellomycetes & & 1 & & & & & & \\
\hline 银耳目 Tremellales & 银耳科 Tremellaceae & 1 & & & & & & 1 \\
\hline
\end{tabular}


表2 地衣型真菌受威胁物种评估等级、分布及用途

Table 2 The evaluated categories, distribution and usage of threatened lichen species. CR, Critically Endangered; EN, Endangered; VU, Vulnerable.

\begin{tabular}{|c|c|c|c|c|c|}
\hline $\begin{array}{l}\text { 物种 } \\
\text { Species }\end{array}$ & $\begin{array}{l}\text { 等级 } \\
\text { Categories }\end{array}$ & $\begin{array}{l}\text { 科 } \\
\text { Family }\end{array}$ & $\begin{array}{l}\text { 地理分布 } \\
\text { Distribution }\end{array}$ & $\begin{array}{l}\text { 中国特有种 } \\
\text { Endemic to } \\
\text { China }\end{array}$ & $\begin{array}{l}\text { 用途 } \\
\text { Usage }\end{array}$ \\
\hline $\begin{array}{l}\text { 顶杯衣 } \\
\text { Acroscyphus } \\
\text { sphaerophoroides }\end{array}$ & 濒危 EN & $\begin{array}{l}\text { 粉衣科 } \\
\text { Caliciaceae }\end{array}$ & $\begin{array}{l}\text { 中国四川、云南、西藏; 印度; 日本; 尼泊尔; 美 } \\
\text { 洲 } \\
\text { China: Sichuan, Yunnan, Tibet; India; Japan; } \\
\text { Nepal; America }\end{array}$ & 否 No & \\
\hline $\begin{array}{l}\text { 裂芽厚枝衣 } \\
\text { Allocetraria isidiigera }\end{array}$ & 易危 VU & $\begin{array}{l}\text { 梅衣科 } \\
\text { Parmeliaceae }\end{array}$ & $\begin{array}{l}\text { 中国西藏 } \\
\text { China: Tibet }\end{array}$ & 是 Yes & \\
\hline $\begin{array}{l}\text { 广开小孢发 } \\
\text { Bryoria divergescens }\end{array}$ & 易危 VU & $\begin{array}{l}\text { 梅衣科 } \\
\text { Parmeliaceae }\end{array}$ & $\begin{array}{l}\text { 中国四川、云南、台湾 } \\
\text { China: Sichuan, Yunnan, Taiwan }\end{array}$ & 是 Yes & \\
\hline $\begin{array}{l}\text { 藏岛衣 } \\
\text { Cetraria xizangensis }\end{array}$ & 易危 VU & $\begin{array}{l}\text { 梅衣科 } \\
\text { Parmeliaceae }\end{array}$ & $\begin{array}{l}\text { 中国西藏 } \\
\text { China: Tibet }\end{array}$ & 是 Yes & \\
\hline $\begin{array}{l}\text { 戴氏石荵 } \\
\text { Cladonia delavayi }\end{array}$ & 易危 VU & $\begin{array}{l}\text { 石荵科 } \\
\text { Cladoniaceae }\end{array}$ & $\begin{array}{l}\text { 中国陕西、四川、云南、西藏; 尼泊尔 } \\
\text { China: Shaanxi, Sichuan, Yunnan, Tibet; Nepal }\end{array}$ & 否 No & $\begin{array}{l}\text { 药用 } \\
\text { Medicinal }\end{array}$ \\
\hline $\begin{array}{l}\text { 拟雀石莣 } \\
\text { Cladonia pseudoevansii }\end{array}$ & 极危 CR & $\begin{array}{l}\text { 石荵科 } \\
\text { Cladoniaceae }\end{array}$ & $\begin{array}{l}\text { 中国吉林; 日本 } \\
\text { China: Jilin; Japan }\end{array}$ & 否 No & \\
\hline $\begin{array}{l}\text { 圆盘衣 } \\
\text { Gymnoderma coccocarpum }\end{array}$ & 濒危 EN & $\begin{array}{l}\text { 石莣科 } \\
\text { Cladoniaceae }\end{array}$ & $\begin{array}{l}\text { 中国湖南、云南、西藏、台湾、广西; 印度、 } \\
\text { 日本; 朝鲜; 韩国; 蒙古; 菲律宾; 泰国; 马来 } \\
\text { 西亚 } \\
\text { China: Hunan, Yunan, Tibet, Taiwan, Guangxi; } \\
\text { India; Japan; North Korea; South Korea; } \\
\text { Mongolia; the Philippines; Thailand; Malaysia }\end{array}$ & 否 No & \\
\hline $\begin{array}{l}\text { 岛圆盘衣 } \\
\text { Gymnoderma insulare }\end{array}$ & 濒危 EN & $\begin{array}{l}\text { 石荵科 } \\
\text { Cladoniaceae }\end{array}$ & $\begin{array}{l}\text { 中国台湾; 日本 } \\
\text { China: Taiwan; Japan }\end{array}$ & 否 No & \\
\hline $\begin{array}{l}\text { 日光山袋衣 } \\
\text { Hypogymnia nikkoensis }\end{array}$ & 易危 VU & $\begin{array}{l}\text { 梅衣科 } \\
\text { Parmeliaceae }\end{array}$ & $\begin{array}{l}\text { 中国内蒙古; 日本 } \\
\text { China: Inner Mongolia; Japan }\end{array}$ & 否 No & \\
\hline $\begin{array}{l}\text { 台湾高山袋衣 } \\
\text { Hypogymnia taiwanalpina }\end{array}$ & 濒危 EN & $\begin{array}{l}\text { 梅衣科 } \\
\text { Parmeliaceae }\end{array}$ & $\begin{array}{l}\text { 中国云南、台湾; 东亚 } \\
\text { China: Yunan, Taiwan; East Asia }\end{array}$ & 否 No & \\
\hline $\begin{array}{l}\text { 金丝绣球 } \\
\text { Lethariella cashmeriana }\end{array}$ & 易危 VU & $\begin{array}{l}\text { 梅衣科 } \\
\text { Parmeliaceae }\end{array}$ & $\begin{array}{l}\text { 中国甘肃、四川、西藏; 印度 } \\
\text { China: Gansu, Sichuan, Tibet; India }\end{array}$ & 否 No & \\
\hline $\begin{array}{l}\text { 金丝刷 } \\
\text { Lethariella cladonioides }\end{array}$ & 易危 VU & $\begin{array}{l}\text { 梅衣科 } \\
\text { Parmeliaceae }\end{array}$ & $\begin{array}{l}\text { 中国山西、陕西、甘肃、青海、四川、 } \\
\text { 云南、西藏; 印度; 尼泊尔 } \\
\text { China: Shanxi, Shaanxi, Gansu, Qinghai, Sichuan, } \\
\text { Yunnan, Tibet; India; Nepal }\end{array}$ & 否 No & $\begin{array}{l}\text { 药用; 石荵试剂 } \\
\text { 原料 } \\
\text { Medicinal and } \\
\text { raw material of } \\
\text { litmus reagent }\end{array}$ \\
\hline $\begin{array}{l}\text { 曲金丝 } \\
\text { Lethariella flexuosa }\end{array}$ & 易危 VU & $\begin{array}{l}\text { 梅衣科 } \\
\text { Parmeliaceae }\end{array}$ & $\begin{array}{l}\text { 中国甘肃、四川、云南、西藏 } \\
\text { China: Gansu, Sichuan, Yunnan, Tibet }\end{array}$ & 是 Yes & $\begin{array}{l}\text { 药用及藏香原料 } \\
\text { Medicinal and } \\
\text { raw material of } \\
\text { Tibetan incense }\end{array}$ \\
\hline $\begin{array}{l}\text { 中华金丝 } \\
\text { Lethariella sinensis }\end{array}$ & 易危 VU & $\begin{array}{l}\text { 梅衣科 } \\
\text { Parmeliaceae }\end{array}$ & $\begin{array}{l}\text { 中国西藏 } \\
\text { China: Tibet }\end{array}$ & 是 Yes & \\
\hline $\begin{array}{l}\text { 金丝带 } \\
\text { Lethariella zahlbruckneri }\end{array}$ & 易危 VU & $\begin{array}{l}\text { 梅衣科 } \\
\text { Parmeliaceae }\end{array}$ & $\begin{array}{l}\text { 中国山西、陕西、四川、贵州、云南、 } \\
\text { 西藏 } \\
\text { China: Shanxi, Shaanxi, Sichuan, Guizhou, } \\
\text { Yunnan, Tibet }\end{array}$ & 是 Yes & $\begin{array}{l}\text { 药用 } \\
\text { Medicinal }\end{array}$ \\
\hline $\begin{array}{l}\text { 密裂大叶梅 } \\
\text { Parmotrema myriolobulatum }\end{array}$ & 极危 CR & $\begin{array}{l}\text { 梅衣科 } \\
\text { Parmeliaceae }\end{array}$ & $\begin{array}{l}\text { 中国云南 } \\
\text { China: Yunnan }\end{array}$ & 是 Yes & \\
\hline $\begin{array}{l}\text { 湖北蜈蚣衣 } \\
\text { Physcia hupehensis }\end{array}$ & 易危 VU & $\begin{array}{l}\text { 蜈蚣衣科 } \\
\text { Physciaceae }\end{array}$ & $\begin{array}{l}\text { 中国湖北 } \\
\text { China: Hubei }\end{array}$ & 是 Yes & \\
\hline $\begin{array}{l}\text { 亚灰大孢衣 } \\
\text { Physconia perisidiosa }\end{array}$ & 易危 VU & $\begin{array}{l}\text { 蜈蚣衣科 } \\
\text { Physciaceae }\end{array}$ & $\begin{array}{l}\text { 中国河北、新疆; 德国 } \\
\text { China: Hebei, Xinjiang; Germany }\end{array}$ & 否 No & \\
\hline $\begin{array}{l}\text { 朝比氏鳞网衣 } \\
\text { Psora asahinae }\end{array}$ & 易危 VU & $\begin{array}{l}\text { 鳞网衣科 } \\
\text { Psoraceae }\end{array}$ & $\begin{array}{l}\text { 中国黑龙江 } \\
\text { China: Heilongjiang }\end{array}$ & 是 Yes & \\
\hline
\end{tabular}


表2 (续) Table 2 (continuous)

\begin{tabular}{|c|c|c|c|c|c|}
\hline $\begin{array}{l}\text { 物种 } \\
\text { Species }\end{array}$ & $\begin{array}{l}\text { 等级 } \\
\text { Categories }\end{array}$ & $\begin{array}{l}\text { 科 } \\
\text { Family }\end{array}$ & $\begin{array}{l}\text { 地理分布 } \\
\text { Distribution }\end{array}$ & $\begin{array}{l}\text { 中国特有种 } \\
\text { Endemic to } \\
\text { China }\end{array}$ & $\begin{array}{l}\text { 用途 } \\
\text { Usage }\end{array}$ \\
\hline $\begin{array}{l}\text { 甘肃地图衣 } \\
\text { Rhizocarpon kansuense }\end{array}$ & 易危 VU & $\begin{array}{l}\text { 地图衣科 } \\
\text { Rhizocarpaceae }\end{array}$ & $\begin{array}{l}\text { 中国甘肃; 中亚 } \\
\text { China: Gansu; Central Asia }\end{array}$ & 否 No & \\
\hline $\begin{array}{l}\text { 华脐鳞 } \\
\text { Rhizoplaca huashanensis }\end{array}$ & 极危 CR & $\begin{array}{l}\text { 茶渍科 } \\
\text { Lecanoraceae }\end{array}$ & $\begin{array}{l}\text { 中国陕西 } \\
\text { China: Shaanxi }\end{array}$ & 是 Yes & \\
\hline $\begin{array}{l}\text { 卧白角衣 } \\
\text { Siphula decumbens }\end{array}$ & 易危 VU & $\begin{array}{l}\text { 霜降衣科 } \\
\text { Icmadophilaceae }\end{array}$ & $\begin{array}{l}\text { 中国台湾、江西; 新西兰 } \\
\text { China: Taiwan, Jiangxi; New Zealand }\end{array}$ & 否 No & \\
\hline $\begin{array}{l}\text { 绿丝槽枝 } \\
\text { Sulcaria virens }\end{array}$ & 易危 VU & $\begin{array}{l}\text { 梅衣科 } \\
\text { Parmeliaceae }\end{array}$ & $\begin{array}{l}\text { 中国四川、云南、西藏、台湾; 印度; } \\
\text { 尼泊尔; 斯里兰卡 } \\
\text { China: Sichuan, Yunnan, Tibet, Taiwan; India; } \\
\text { Nepal; Sri Lanka }\end{array}$ & 否 No & $\begin{array}{l}\text { 药用 } \\
\text { Medicinal }\end{array}$ \\
\hline $\begin{array}{l}\text { 阿尔泰石耳 } \\
\text { Umbilicaria altaiensis }\end{array}$ & 濒危 EN & $\begin{array}{l}\text { 石耳科 } \\
\text { Umbilicariaceae }\end{array}$ & $\begin{array}{l}\text { 中国新疆 } \\
\text { China: Xinjiang }\end{array}$ & 是 Yes & \\
\hline $\begin{array}{l}\text { 庐山石耳 } \\
\text { Umbilicaria esculenta }\end{array}$ & 易危 VU & $\begin{array}{l}\text { 石耳科 } \\
\text { Umbilicariaceae }\end{array}$ & $\begin{array}{l}\text { 中国黑龙江、吉林、辽宁、安徽、浙江、江西、 } \\
\text { 湖南、湖北、云南、西藏、 } \\
\text { 广西; 日本; 朝鲜; 韩国 } \\
\text { China: Heilongjiang, Jilin, Liaoning, Anhui, } \\
\text { Zhejiang, Jiangxi, Hunan, Hubei, Yunan, Tibet, } \\
\text { Guangxi; Japan; North Korea; South Korea }\end{array}$ & 否 No & $\begin{array}{l}\text { 食药用 } \\
\text { Edible and } \\
\text { medicinal }\end{array}$ \\
\hline $\begin{array}{l}\text { 周裂石耳 } \\
\text { Umbilicaria loboperipherica }\end{array}$ & 易危 VU & $\begin{array}{l}\text { 石耳科 } \\
\text { Umbilicariaceae }\end{array}$ & $\begin{array}{l}\text { 中国吉林、辽宁、内蒙、陕西、河北、云南 } \\
\text { China: Jilin, Liaoning, Inner Mongolia, Shaanxi, } \\
\text { Hebei, Yunnan }\end{array}$ & 是 Yes & \\
\hline $\begin{array}{l}\text { 皮芽石耳 } \\
\text { Umbilicaria squamosa }\end{array}$ & 濒危 EN & $\begin{array}{l}\text { 石耳科 } \\
\text { Umbilicariaceae }\end{array}$ & $\begin{array}{l}\text { 中国云南、西藏、广西 } \\
\text { China: Yunnan, Tibet, Guangxi }\end{array}$ & 是 Yes & \\
\hline $\begin{array}{l}\text { 太白石耳 } \\
\text { Umbilicaria taibaiensis }\end{array}$ & 濒危 EN & $\begin{array}{l}\text { 石耳科 } \\
\text { Umbilicariaceae }\end{array}$ & $\begin{array}{l}\text { 中国陕西、云南、四川 } \\
\text { China: Shaanxi, Yunnan, Sichuan }\end{array}$ & 是 Yes & \\
\hline
\end{tabular}

估地衣物种总数的 $0.28 \%$; 无危 657 种，占比 $30.36 \%$; 数据不足 1,473 种, 占比 $68.07 \%$ 。我国需要关注和保 护的地衣达1,507种(指受威胁、近危和数据不足的 物种), 占被评估地衣物种总数的 $69.64 \%$ 。

\section{4 各受威胁等级的物种情况}

\section{1 极危}

在本次评估中, 被评为极危的地衣有 3 种, 为 拟雀石荵(Cladonia pseudoevansii)、密裂大叶梅 (Parmotrema myriolobulatum) 和华脐鳞(Rhizoplaca huashanensis)。其中拟雀石荵属于石芯科, 在我国 仅分布于吉林长白山西南坡, 其生境退化, 生存状 况堪忧。密裂大叶梅属于梅衣科, 仅分布于云南, 分布范围狭窄，种群数量少，作为新种发表后鲜有 新增的采集记录。华脐鳞属于茶渍科, 仅分布于陕 西华山, 自报道新种描述以来, 亦鲜有新增的采集 记录。三种极危地衣的具体信息如下(图1)。

\subsection{1 拟雀石荵}

Cladonia pseudoevansii Asahina, Journal of Japanese Botany 16: 187 (1940) (图1A)

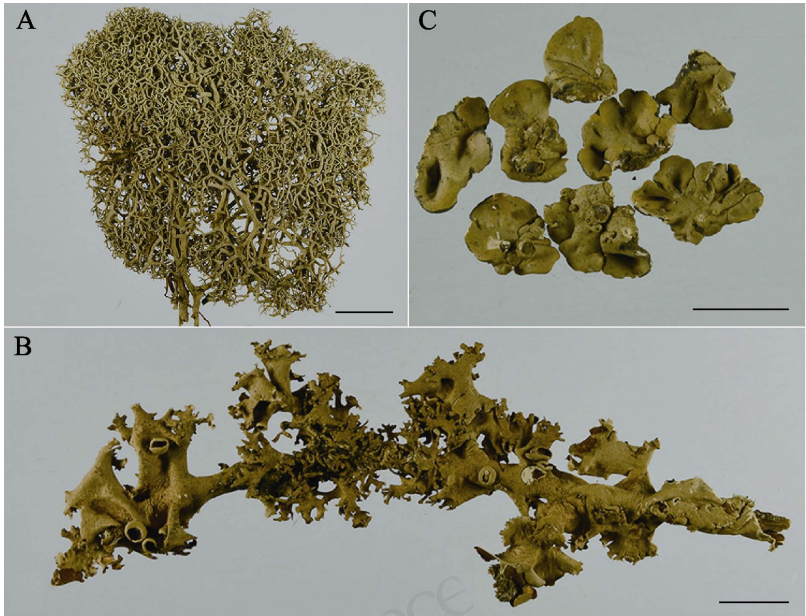

图1 三种极危地衣的形态图。(A)拟雀石荵(HMAS-L-16743); (B) 密裂大叶梅 (HMAS-L-18613); (C) 华脐鳞 (主模式, HMAS-L-3747)。标尺均为 $1 \mathbf{c m}$ 。

Fig. 1 Morphology of three Critically Endangered lichen species. (A) Cladonia pseudoevansii (HMAS-L-16743); (B) Parmotrema myriolobulatum (HMAS-L-18613); (C) Rhizoplaca huashanensis (holotype, HMAS-L-3747). Scale bars $=1 \mathrm{~cm}$.

三 Cladina pseudoevansii (Asahina) Hale \& W. L. Culb., Bryologist 73 (3): 510 (1970). 
初生地衣体未见。果柄近直立, 灰白色, 直径 0.5-1 mm, 缺乏皮层, 分枝繁茂, 树枝状, 等二叉 多次分枝, 外形貌似一堆绣球或群集的小鸟; 果柄 圆筒形, 中空, 顶端无杯状扩大, 在主要分叉处具 圆孔。子囊盘和分生狍子器未见。

化学: 含有松萝酸和珠光酸。

基物：地上。

凭证标本: 吉林长白山, $1,750 \mathrm{~m}, 1980.9 .1$, 胡 玉琛 2461 (HMAS-L-16743); 2,200 m, 1982. 8. 19, 胡玉琛 3641 (HMAS-L-21057); 2,000 m, 1983. 8. 1, 魏江春和陈健斌 6399-1 (HMAS-L-6600); 1,600 m, 1983. 8. 5, 魏江春和陈健斌 6620 (HMAS-L-6602), 6621 (HMAS-L-6597); 1,540 m, 1983. 8. 7, 魏江春和 陈健斌 6,696 (HMAS-L-6596); 1,600-1,700 m, 1983. 8. 9, 魏江春和陈健斌 6780-1 (HMAS-L-6603); 1,500 m, 1994. 8. 4, 魏江春等94254 (HMAS-L-18153).

国内文献记载: 吉林(Ahti，1961，p.26; 陈锡龄 等, 1981, p.133; Wei et al, 1986, p.241).

分布：中国(吉林), 日本。

地理成分: 东亚成分。

讨论：该种最初以Cladonia pseudoevansii发表 (Asahina，1940)，依据的模式标本于1923年采集自 日本。Hale和Culberson (1970)将其组合至Cladina属 中。但很多地衣学家并不认可Cladina属, 尤其是系 统发育分析结果显示Cladina属处于Cladonia属的 分支内，并未形成单系(Stenroos et al，2002，2015， 2019; Guo \& Kashiwadani, 2004)。Athukorala等(2016) 基于 ITS 和线粒体小亚基(mtSSU)序列分析支持 Stenroos等(2002)的结果。因此该种仍以 Cladonia pseudoevansii为正名。Cladonia pseudoevansii的汉语 名为拟雀石荵, 该种与雀石芯(Cladonia stellaris (Opiz) Pouzar \& Vězda)地衣体外形非常相似, 但因 该种的果柄具明显的二叉分枝特征可与雀石荵相 区分。

拟雀石荵在国内的报道仅见于吉林长白山(Ahti, 1961; 陈锡龄等, 1981; Wei et al, 1986), 其中Ahti (1961)在报道中提到的采集地点“Changpai-san”、 “Chang-pei-shan”和“Pehtausan”实际均为长白山。虽 然该种属于东亚成分，但在进行红色名录评估过程 中, 主要还是依据其地理分布范围(分布区和占有 面积)非常有限, 按照IUCN红色名录受威胁等级评 估标准中的B1ab(iii)和2ab(iii), 而将其评定为极危
(CR)。但随着后续参考文献的不断更新及完善, 我 们发现Athukorala等(2016)对北美石莣类地衣的系 统发育学分析所用的实验材料中包括了产自阿拉 斯加的拟雀石荵标本，因此拟雀石荵的分布地范围 需进一步确认，如确定该种分布地包括日本、中国 和北美，其目前审定的受威胁等级为极危的结果需 调整。

\subsection{2 密裂大叶梅}

Parmotrema myriolobulatum (J. D. Zhao) J. C. Wei, An Enumeration of Lichens in China: 178-179 (1991) (图1B)

三 Parmelia myriolobulata J. D. Zhao, Acta Phytotaxonomica Sinica 9 (2): 165 (1964).

地衣体叶状, 宽度可达 $15 \mathrm{~cm}$, 较疏松地着生 于基物; 裂片不规则分裂, 5-10 mm宽，顶端多齿裂， 边缘重复分裂小裂片状, 1-2 mm宽, 顶端稍平或渐 尖，呈珊瑚状; 上表面灰色至灰绿色，久置标本室 后呈淡灰黄色或淡烟色; 髓层白色, 下表面黑色, 周边裸露带淡褐色至褐色，具网纹或皱褶; 假根稀 少, 黑色, 单一不分叉, 极短, 长度约 $0.5 \mathrm{~mm}$ 。子囊 盘有短柄，盘状或杯状，盘径2-8 mm，盘缘完整， 稍向内卷，盘面褐色至深褐色，无穿孔，果托表面 较光滑至明显白斑, 无缘毛和小裂片。子囊宽棒状, 大小为 $37.5 \times 20-22.5 \mu \mathrm{m}$; 子囊孢子单胞, 无色, 长椭圆形，大小为20-22.5 × 7.5-10 $\mu \mathrm{m}$ 。

化学: 含有黑茶渍素、氯黑茶渍素、原岛衣酸 和维任西酸。

基物：树皮。

凭证标本：云南西双版纳景洪预养，1960. 11. 24, 赵继鼎和陈玉本3587 (HMAS-L-18613)，3573 (HMAS-L-10619)，3574 (HMAS-L-120618); 思茅, 1960. 11, 赵继鼎和陈玉本 3649 (HMAS-L-16175), 3695a (HMAS-L-16176).

国内文献记载：云南(赵继鼎等，1982，p.53; Chen et al, 2005, p.104; 陈健斌, 2015, p.191).

分布: 中国云南。

地理成分：中国特有种。

讨论：该种的主要特征为裂片呈珊瑚状, 无缘 毛，边缘具有重复分裂的小裂片; 上表面无粉芽和 裂芽，子囊盘盘面无穿孔，果托表面常有白斑，髓 层含有的主要化学成分为原岛衣酸。该种与Parmotrema merrillii (Vain.) Hale地衣体外形相似, 但 
Parmotrema merrillii的子囊盘果托上有缘毛和小裂 片; 而该种主模式标本的子囊盘果托表面光滑, 副 模式标本的果托常有明显白斑和网状皱褶, 但未见 缘毛和小裂片。该种最初以Parmelia myriolobulata J. D. Zhao (赵继鼎，1964)报道，后被Wei (1991)组合 至大叶梅属 (Parmotrema) 中, 现名为密裂大叶梅 (Parmotrema myriolobulatum)。该种为中国特有种, 已知仅分布于云南景洪市和思茅区。

在进行红色名录评估过程中, 因该种的生存状 态为: 分布点集中于同一省份内相互毗邻的两县级 行政单位; 作为中国特有种，自1964年(距今55年) 以Parmelia myriolobulata (标本采集于1960年)发表 后, 在其他相关的记录和研究中(赵继鼎等, 1982; Chen et al, 2005, 陈健斌, 2015)再无新增任何标本。 依据 IUCN 红色名录受威胁等级评估标准中的 $\mathrm{A} 4 \mathrm{ac} 、 \mathrm{~B} 1 \mathrm{ab}(\mathrm{ii})+2 \mathrm{ab}(\mathrm{ii})$ 和D2, 并参考作为新种发表 后未再发现的年限(30-50年), 将该种的受威胁等级 评定为极危 $(\mathrm{CR})$ 。

\subsection{3 华脐鳞}

Rhizoplaca huashanensis J. C. Wei, Acta Mycologica Sinica 3 (4): 208 (1984) (图1C)

地衣体盾叶状, 近圆形, 单叶型, 厚而坚硬, 直径可达 $1.5 \mathrm{~cm}$; 裂片宽4-8 mm; 上表面黄绿色, 光滑, 向外辐射有裂纹, 中央凹陷, 周围鼓起; 下 表面黑色, 无光泽, 中央具脐状物使地衣体固着于 基物表面。子囊盘茶渍型, 幼小时盘面与地衣体上 表面同色，成熟后呈褐色至黑色，直径可达近 $3 \mathrm{~mm}$, 常覆盖白色粉霜层。子囊棍棒状, 大小为50-62.5 $\times$ 11.25-12.5 $\mu \mathrm{m}$; 子囊狍子单胞, 无色, 长椭圆形, 大小为 $11.25-15 \times 5-7.5 \mu \mathrm{m}$ 。

化学: 含有松萝酸。

基物: 岩石。

凭证标本：陕西华山，1964.6.15，魏江春 59 (holotype, HMAS-L-3747); 1,500-1,700 m, 1998. 7. 31, 魏江春等 s. n. (HMAS-L-21174, 21175, 21176, 21177, 113683, 113685); 1998. 8. 1, 魏江春等 s. n. (HMAS-L-21178, 21179, 113684); 1999. 10. 5, 魏江 春 s. n. (HMAS-L-18357).

国内文献记载: 陕西(魏江春 1984, p. 208). 分布: 中国陕西。 地理成分：中国特有种。 讨论：该种与垫脐鳞(Rhizoplaca melanophth- alma (DC.) Leuckert)和盾脐鳞(Rhizoplaca peltata (Ramond) Leuckert \& Poelt)相似, 但是, 该种地衣 体为单叶型, 下表面为黑色, 而垫脐鳞的地衣体为 复叶型，呈垫状，其下表面脐周为褐色，叶缘为蓝 黑色; 该种地衣体下表面光滑, 含有松萝酸, 而盾 脐鳞的地衣体下表面粗粘, 含泽屋萜(魏江春, 1984)。该种为中国特有种，分布地极为狭窄，仅已 知分布于陕西华山。本文作者魏江春曾试图通过移 植法，将采集自陕西华山的华脐鳞连带基物移至河 北雾灵山，以扩大其分布范围达到保育的目的，但 未获成功。

在进行红色名录评估过程中，因该种的生存状 态为：分布点仅 1 个; 作为中国特有种，自1984年 (距今35年)发表后, 新增标本信息较少。依据IUCN 红色名录受威胁等级评估标准中的A4ac、B1ab(ii, iii) + 2ab(ii, iii)和D2, 并参考作为新种发表后发生 量少(最近采集记录距今 20 年), 将该种的受威胁等 级评定为极危 $(\mathrm{CR})$ 。

\section{2 濒危}

被评为濒危的地衣共7种, 其中 2 种属于石荵科, 3 种属于石耳科, 1 种属于梅衣科, 1 种属于粉衣科(表 2)。石耳科中的阿尔泰石耳(Umbilicaria altaiensis) 仅分布于新疆，太白石耳(U. taibaiensis)分布于陕 西、云南及四川，皮芽石耳(U. squamosa)分布于云 南、西藏和广西, 均为中国特有种, 分布较为狭窄。 阿尔泰石耳和皮芽石耳种群数量少, 新种发表后鲜 有新增的采集记录。太白石耳只在太白山的部分区 域分布，自1984年作为新种描述发表之后，研究人 员在该模式产地最近的采集记录为1998年，之后未 见报道。粉衣科中的顶杯衣属(Acroscyphus)为单种 属, 仅顶杯衣一种, 具有较高的学术研究价值, 分 布于我国云南、西藏、四川等省有限的几个地点，且 其栖息地严重退化和碎片化，处于濒危状态。

\section{3 易危}

被评为易危的地衣共18种(表2), 其中6种是中 国特有种, 即裂芽厚枝衣(Allocetraria isidiigera)、藏 岛衣(Cetraria xizangensis)、中华金丝(Lethariella sinensis)、湖北蜈蚣衣(Physcia hupehensis)、朝比氏 鳞网衣(Psora asahinae)和周裂石耳(Umbilicaria loboperipherica)。这些物种大多分布范围较窄，只 在一个或两个省区有报道, 但种群及个体数量相对 较多, 且受人类干扰程度较低, 处于易危状态。此 
外，金丝刷、金丝带、绿丝槽枝和庐山石耳(U. esculenta) 分布相对广泛, 但由于具有一定的食药用 价值而遭受不同程度的采挖破坏, 种群出现波动、 个体数量减少, 如不采取保护措施, 可能陷入濒危 甚至极危状态。

\section{4 近危}

被评为近危的地衣共6种, 包括球孔衣(Coccotrema cucurbitula)、长丝萝(Dichousnea longissima)、 近祁连鸡皮衣(Pertusaria paraqilianensis)、地茶 (Thamnolia vermicularis)、亚直角松萝(Usnea subrectangulata)和亚粗壮松萝( $U$. subrobusta)。其中地 茶和松萝具有一定的药用价值, 开发利用对其造成 一定影响, 但由于其分布较广、资源储量较大, 尚 未达到受威胁状态。若人为干扰无法得到有效遏制, 这些物种则可能受到威胁。

\section{5 受威胁物种的地理分布}

上述受威胁的 28 种地衣在各省区呈不均匀分 布。以西藏和云南分布的物种最多, 均有 12 种, 占 受威胁地衣物种数的 $42.86 \%$ 。其他各省区依次为四 川8种，陕西6种，台湾5种，甘肃4种，新疆3种，黑 龙江、吉林、山西、江西、湖南、湖北和广西各 2 种, 辽宁、内蒙古、河北、青海、安徽、浙江和贵 州各1种(表2)。西藏、云南、四川和陕西是受威胁 地衣集中分布的地区, 是地衣保护需重点关注的地 区。在受威胁的地衣中, 有 11 种是中国特有种, 包 括裂芽厚枝衣、藏岛衣、中华金丝、密裂大叶梅、 湖北蜈蚣衣、朝比氏鳞网衣、华脐鳞、阿尔泰石耳、 周裂石耳、皮芽石耳和太白石耳等(表2), 占受威胁 地衣的 $39.29 \%$ 。受威胁的 11 种中国特有地衣分布分 散，除周裂石耳、皮芽石耳和太白石耳分布于 3 个省 区以上外，其余种均仅分布于一个省区，即西藏分 布3种，云南、陕西、新疆、黑龙江和湖北各分布1种。

\section{6 与已有评估结果的对比}

本次评估出的28种受威胁地衣, 与2017年公布 的云南省生物物种红色名录中的13种云南省省级 受威胁物种相比, 仅 3 种评估等级相似, 比如: 云南 省濒危的圆盘衣在全国范围也属于濒危，云南省易 危的金丝刷和绿丝槽枝在全国也属于易危。评估受 威胁程度不同的4种，如云南省极危种金丝带在全 国范围属于易危，云南省濒危的曲金丝在全国范围 属于易危, 云南省易危的顶杯衣和近危的广开小孢 发在全国范围属于濒危。云南省其他6种受威胁地
衣在本次全国范围评估中不在受威胁等级之列。

\section{对地衣生物多样性保护的展望及建议}

本次评估中地衣受威胁种数占总评估种数的 比例极低，仅为 $1.29 \%$; 不受威胁的无危物种也仅 占 $30.36 \%$, 而 $68.07 \%$ 的物种属于数据不足。这一数 据凸显了我国地衣学研究的严峻形势及对地衣分 类学人才的迫切需要。首先, 中国地衣分类学研究 基础较弱, 物种名称鉴定的准确度不高; 其次, 物 种研究的基础数据不足, 缺乏足够的野外考察和长 期监测的基本数据，导致大量物种的现有数据信息 不足以支持可靠的红色名录等级评定; 第三，因地 衣分类学与明显的国计民生联系不紧密，加之评价 体系的弊端，使得潜心钻研地衣分类学、综合能力 强、整体素质高的青年人才匮乏。

地衣自身生长缓慢, 对环境污染敏感, 并且绝 大多数分布区域狭窄，种群数量少，对生境退化的 响应和恢复生长的能力较弱, 因此人类活动导致的 栖息地破坏是使地衣物种受威胁的主要原因。典型 的如戴氏石荵(Cladonia delavayi)仅分布于西藏少 数几个地点以及陕西秦岭太白山的一个小台地上; 华脐鳞由于受环境变化以及旅游开发的影响，栖息 地退化，生存受到严重威胁，目前已难受其踪迹。 而庐山石耳、金丝刷等具有食药用价值的地衣，不 受控制的大规模采收利用已经使其种群受到很大 影响，前者甚至在庐山等分布区已几近绝迹。此外， 很多地衣对基物的要求苛刻, 特异性较强, 如药用 地衣金丝刷，只在特定的高山植物树枝上生长，森 林砍伐对其造成严重威胁。

对于中国地衣生物多样性的保护我们有以下 建议: (1)参考本次评估中地衣的受威胁等级, 出台 专门的政策法规，扩大地衣资源的保护区范围，同 时加强保护区对受威胁物种的保护力度，防止过度 采集和开发利用地衣资源, 平衡生物资源保护与利 用的关系，实现对地衣资源的可持续利用。(2)加大 研究经费的投入力度, 对中国地衣的多样性及分布 进行更为深入的本底调查，提升对其受威胁程度的 客观评估能力, 避免因缺乏研究而导致数据不足, 最终造成保护不利的后果。(3)目前开发利用的对象 主要是自然界中的地衣体，一般生长极其缓慢，过 度采集后极难恢复, 会有引发灭绝的风险。因此若 要永续利用地衣资源, 必须转向实验室内人工培养, 
从物种、化学及基因等不同层次研发地衣资源利用 新技术。最终做到保护与开发应用并行, 在人类健 康和绿色农业等领域最大程度挖掘地衣资源的利 用价值和开发潜力。

致谢：本研究得到姚一建研究员的大力支持，全国 地衣专家学者及部分青年学生提供地衣物种信息 并协助审核地衣红色名录。在此，我们对上述各位 专家、老师和同事同行表示衰心的感谢!

\section{参考文献}

Ahti T (1961) Taxonomic studies on reindeer lichens (Cladonia, subgenus Cladina). Annales Botanici Societatis Zoologicae Botanicae Fennicae 'Vanamo', 32, 1-160.

Asahina Y (1940) Mikrochemischer Nachweis der Flechtenstoffe. XI. Mitteilung. Journal of Japanese Botany, 16, 185-193.

Athukorala SNP, Pino-Bodas R, Stenroos S, Ahti T, Piercey-Normore MD (2016) Phylogenetic relationships among reindeer lichens of North America. Lichenologist, 48, 209-227.

Baillie JEM, Hilton-Taylor C, Stuart SN (2004) 2004 IUCN Red List of Threatened Species ${ }^{\mathrm{TM}}$. A Global Species Assessment. IUCN, Gland, Switzerland \& Cambridge, UK.

Chen J, Blume H, Beyer L (2000) Weathering of rocks induced by lichen colonization - A review. Catena, 39, 121-146.

Chen JB (2015) Flora Lichenum Sinicorum, Vol. 4, Parmeliaceae (I). Science Press, Beijing. (in Chinese) [陈健斌 (2015) 中国地衣志第四卷: 梅衣科(I). 科学出版社, 北京.]

Chen JB, Wang SL, Elix JA (2005) Parmeliaceae (Ascomycota) lichens in China's mainland III. The genus Parmotrema. Mycotaxon, 91, 93-113.

Chen XL, Zhao CF, Luo GY (1981) A list of lichens in N. E. China. Journal of North-Eastern Forestry Institute, 3, 127-135. (in Chinese with English abstract) [陈锡龄, 赵从福, 罗光 裕 (1981) 东北地衣名录. 东北林学院学报, 3, 127-135.]

Church JM, Coppins BJ, Gilbert OL, James PW, Stewart NF (1996) Red Data Books of Britain and Ireland: Lichens. Volume 1: Britain. Joint Nature Conservation Committee, Peterborough.

de Grammont PC, Cuarón AD (2006) An evaluation of threatened species categorization systems used on the American continent. Conservation Biology, 20, 14-27.

Glowka L, Burhenne-Guilmin F, Synge H, McNeely JA, Gündling L (translated by Scientific Committee of Endangered Species of the People's Republic of China, Committee on Biodiversity, Chinese Academy of Sciences) (1997) A Guide to the Convention on Biological Diversity, pp. 1-131. Science Press, Beijing. (in Chinese) [中华人民共和国濒危 物种科学委员会, 中国科学院生物多样性委员会(译) (1997) 生物多样性公约指南. 科学出版社, 北京.]
Guo SY, Kashiwadani H (2004) Recent study on the phylogeny of the genus Cladonia (s. lat.) with the emphasis on the integrative biology. National Science Museum Monographs, Tokyo, 24, 207-225.

Hale ME, Culberson WL (1970) A fourth checklist of the lichens of the continental United States and Canada. Bryologist, 73, 499-543.

Hawksworth DL (1991) The fungal dimension of biodiversity: magnitude, significance, and conservation. Mycological Research, 6, 641-655.

Kirk PM, Cannon PF, Minter DW, Stalpers JA (2008) Dictionary of the Fungi. 10th edn. CAB International, Wallingford

Larson DW (1987) The absorption and release of water by lichens. In: Progress and Problems in Lichenology in the Eighties, Bibliotheca Lichenologica, 25 (ed. Peveling E), pp. 351-360. J. Cramer, Berlin-Stuttgart.

Lindsay D (1978) The role of lichens in Antarctic ecosystems. Bryologist, 81, 268-276.

Lücking R, Hodkinson BP, Leavitt SD (2017) The 2016 classification of lichenized fungi in the Ascomycota and Basidiomycota-Approaching one thousand genera. Bryologist, 119, 361-416.

Mace GM, Lande R (1991) Assessing extinction threats: Toward a re-evaluation of IUCN threatened species categories. Conservation Biology, 5, 148-157.

Miller RM, Rodríguez JP, Aniskowicz-Fowler T, Bambaradeniya C, Boles R, Eaton MA, Gärdenfors U, Keller V, Molur S, Walker S, Pollock C (2007) National threatened species listing based on IUCN criteria and regional guidelines: Current status and future perspectives. Conservation Biology, 21, 684-696.

Mitrović T, Stamenković S, Cvetković V, Tošić S, Stanković M, Radojević I, Stefanović O, Comić L, Dačić D, Curčić M, Marković S (2011) Antioxidant, antimicrobial and antiproliferative activities of five lichen species. International Journal of Molecular Sciences, 12, 5428-5448.

Neamati N, Hong H, Mazumder A, Wang S, Sunder S, Nicklaus MC, George, WAM, Proksa B, Pommier Y (1997) Depsides and depsidones as inhibitors of HIV-1 integrase: Discovery of novel inhibitors through 3D database searching. Journal of Medicinal Chemistry, 40, 942-951.

Pavlovic V, Stojanovic I, Jadranin M, Vajs V, Djordjevic I, Smelcerovic A, Stojanovic G (2012) Effect of four lichen acids isolated from Hypogymnia physodes on viability of rat thymocytes. Food and Chemical Toxicology, 51, 160-164.

Randlane T, Jüriado I, Suija A, Lõhmus P, Leppik E (2008) Lichens in the new Red List of Estonia. Folia Cryptogamica Estonica, 44, 113-120.

Randlane T (1998) Red list of Estonian macrolichens. Folia Cryptogamica Estonica, 32, 75-79.

Ranković B, Mišić M, Sukdolak S (2008) The antimicrobial activity of substances derived from the lichens Physcia aipolia, Umbilicaria polyphylla, Parmelia caperata and 
Hypogymnia physodes. World Journal of Microbiology and Biotechnology, 24, 1239-1242.

Spribille T, Tuovinen V, Resl P, Vanderpool D, Wolinski H, Aime MC, Schneider K, Stabentheiner E, Toome-Heller M, Thor G, Mayrhofer H, Johannesson H, McCutcheon JP (2016) Basidiomycete yeasts in the cortex of ascomycete macrolichens. Science, 353, 488-491.

Stenroos S, Hyvonen J, Myllys L, Thell A, Ahti T (2002) Phylogeny of the genus Cladonia s. lat. (Cladoniaceae, Ascomycetes) inferred from molecular, morphological, and chemical data. Cladistics, 18, 237-278.

Stenroos S, Pino-Bodas R, Weckman D, Ahti T (2015) Phylogeny of Cladonia uncialis (Cladoniaceae, Lecanoromycetes) and its allies. Lichenologist, 47, 215-223.

Stenroos S, Pino-Bodas R, Hyvonen J, Lumbschc HT, Ahti T (2019) Phylogeny of the family Cladoniaceae (Lecanoromycetes, Ascomycota) based on sequences of multiple loci. Cladistics, 35, 351-384.

Vié JC, Hilton-Taylor C, Pollock C, Ragle J, Smart J, Stuart SN, Tong R (2008) The IUCN Red List: A key conservation tool. In: The 2008 Review of the IUCN Red List of Threatened Species (eds Vié JC, Hilton-Taylor C, Stuart SN). IUCN, Gland, Switzerland.

Wang K, Liu DM, Cai L, Wu HJ, Li Y, Wei TZ, Wang YH, Wu HM, Wei XD, Li BB, Li JS, Yao YJ (2020) Methods and procedures of the red list assessment of macrofungi in China. Biodiversity Science, 28, 11-19. (in Chinese with English abstract) [王科, 刘冬梅, 蔡蕾, 吴海军, 李熠, 魏
铁铮, 王永会, 吴红梅, 卫晓丹, 李斌斌, 李俊生, 姚一 建 (2020) 中国大型真菌红色名录评估方法和程序. 生 物多样性, 28, 11-19.]

Wei JC (1984) A preliminary study of the lichen genus Rhizoplaca from China. Acta Mycologica Sinica, 3, 207-213. (in Chinese with English abstract) [魏江春 (1984) 中国脐鳞 属地衣的初步研究. 真菌学报, 3, 207-213.]

Wei JC (1991) An Enumeration of Lichens in China. International Academic Publishers, Beijing.

Wei JC (2020) The Enumeration of Lichenized Fungi in China. China Forestry Publishing House, Beijing (in press).

Wei JC, Chen JB, Jiang YM (1986) Studies on lichen family Cladoniaceae in China. Acta Mycologica Sinica, 5, 240-250.

Woods RG, Coppins BJ (2003) A Conservation Evaluation of British Lichens. British Lichen Society, London.

Woods RG, Coppins BJ (2012) A Conservation Evaluation of British Lichens and Lichenicolous Fungi. Species Status 13. Joint Nature Conservation Committee, Peterborough.

Zhao JD (1964) A preliminary study on Chinese Parmelia. Acta Phytotaxonomica Sinica, 9, 139-166. (in Chinese with English abstract) [赵继鼎 (1964) 中国梅花衣属的初步研 究. 植物分类学报, 9, 139-166.]

Zhao JD, Xu LW, Sun ZM (1982) Prodromus Lichenum Sinicorum. Science Press, Beijing. (in Chinese) [赵继鼎, 徐连 旺, 孙增美 (1982) 中国地衣初编. 科学出版社. 北京.]

(责任编委: 杨祝良 责任编辑: 黄祥忠) 